\section{O TORNAR-SE ARTURO REVELADO NA FESTA DE NOSSA SENHORA DO ROSÁRIO: SABERES E PRÁTICAS COMPARTILHADOS NOS ENTRELAÇAMENTOS COTIDIANOS}

\author{
BECOMING AN ARTURO REVEALED IN THE "FESTIVAL OF OUR LADY OF THE \\ ROSARY": KNOWLEDGES AND PRACTICES SHARED IN EVERYDAY RELATIONSHIPS
}

EL VOLVERSE "ARTURO" REVELADO EN LA "FIESTA DE NUESTRA SEÑORA DEL ROSARIO": SABERES Y PRACTICAS COMPARTIDAS EN LAS RELACIONES COTIDIANAS

José Alfredo Oliveira Debortoli", Karla Tereza Ocelli Costa*
Palavras chave:

Grupo com ancestrais do continente africano. Características culturais.

Conhecimento. Aprendizagem.
Resumo: Apresentamos neste artigo aspectos do cotidiano da Comunidade dos Arturos que se revelaram em experiências culturais. Para tanto, realizamos um estudo etnográfico entre 2011 e 2012, buscando mergulhar em sua prática festiva. Optamos pela observação participante, utilizando o recurso do caderno de campo e de entrevistas informais e semiestruturadas. As respostas encontradas ganharam centralidade e visibilidade não apenas em sujeitos tomados de forma isolada, nem em uma estrutura estática de signos determinantes da organização da vida social, nosso foco analítico voltou-se para a Festa de Nossa Senhora do Rosário. 0 tornar-se Arturo revelou-se como constituinte de uma aprendizagem na prática, influenciada sistematicamente por ações cotidianas nas quais fazer/aprender envolve relações de poder, acordos, negociações e conflitos inerentes à vida social. Este estudo contribuiu para que ampliássemos o foco de compreensão da escola, movendo-nos em direção a contextos de relações nos quais se revelam diferentes modos de organização da vida social.

Keywords: African continental ancestry group. Cultural characteristics. Knowledge. Learning.

\begin{abstract}
This article presents aspects of everyday life in the Arturos' Community, which have been revealed in cultural experiences. Between 2011 and 2012, we conducted an ethnographic study in order to delve in their festive practices. We chose participant observation using field books as well as informal and semi-structured interviews. The responses gained significance and visibility not only in individual subjects or in a static structure of determinant signs of social life organization. Rather, our analytical focus was on the "Festival of Our Lady of the Rosary". Becoming an Arturo turned out to be part of practical learning systematically influenced by daily actions in which doing/ learning involve power relationships, agreements, negotiations and conflicts inherent to social life. This study helped us to expand our focus of understanding about school, displacing us towards relationship contexts that reveal different kinds of social life organization.
\end{abstract}

Resumen: En este artículo presentamos aspectos de la vida cotidiana de la Comunidad de los Arturos que han sido reveladas en experiencias culturales. Para ello, realizamos un estudio etnográfico entre 2011 y 2012, con el propósito de explorar sus prácticas festivas. Escogimos la observación participativa, utilizando el recurso del cuaderno de campo y entrevistas informales y semiestructuradas. Las respuestas recogidas ganaron centralidad y visibilidad no sólo en sujetos tomados de manera aislada o en una estructura estática de signos determinantes de la organización de la vida social. Nuestro foco de análisis se centró en la "Fiesta de Nuestra Señora del Rosario". El volverse Arturo se reveló como constituyente de un aprendizaje en la práctica, influenciado sistemáticamente por acciones cotidianas en las cuales hacer/aprender implican relaciones de poder, acuerdos, negociaciones y conflictos inherentes a la vida social. Este estudio contribuyó a expandir el foco de comprensión de la escuela, llevándonos hacia contextos de relaciones en los que se revelan diferentes modos de organización de la vida social.
*Universidade Federal de Minas Gerais Belo Horizonte, MG, Brasil. E-mail: dbortoli@eeffto.ufmg.br

Recebido em: 29-07-2015 Aprovado em: 08-03-2016

\section{(c) (1) () Licence}




\section{ABERTURA}

"Sou um Arturo, sou filho do Rosário, ele me protege do mundo".

Assim se apresentaram os Arturos, quando de nossa primeira visita à comunidade. Descobrir o percurso para se constituir um Arturo nos intrigou desde o início. Que sentimento é este que emerge na relação com o outro, ocupando espaço, tornando-se presente e forte? Aprende-se a ser Arturo? Essas questões borbulhavam em nossa mente e nos fizeram buscar adentrar neste mundo de luta, de resistência, de coletividade. Muito pouco sabíamos sobre 0 cotidiano dessa comunidade, suas práticas e suas festas.

Mas, quem são os Arturos e por que estudá-los?

Uma de nossas maiores inquietações era a de que, das tantas identidades possíveis de serem constituídas também no ambiente escolar, percebíamos ainda entre os estudantes muita resistência em assumir uma identidade negra ${ }^{1}$.

A partir de 2003, com a promulgação da Lei 10.639, que torna obrigatório o ensino sobre História e Cultura Afro-Brasileira nos estabelecimentos de ensino fundamental e médio, oficiais e particulares, abriu-se espaço para que se expandisse o estudo da cultura africana e afro-brasileira. Mesmo que ainda de forma tímida, houve repercussões pedagógicas importantes no sentido do reconhecimento pela escola da necessidade de valorizar a história e cultura da população brasileira, buscando também reparar danos provocados pela omissão da contribuição dos africanos e afrodescendentes na história e formação do povo brasileiro.

Decidimos, então, investigar se o brincar festejando e/ou festejar brincando poderia ter influência na construção de uma identidade. Buscamos entender que relações emergem a partir da participação da Comunidade dos Arturos na Festa do Reinado de Nossa Senhora do Rosário, sabendo que esta participação é construída na relação com seus pares influenciados pela estrutura de rede social (família, comunidade, escola etc.), processos educativos e acesso a bens materiais e culturais.

A Comunidade dos Arturos está localizada no município de Contagem e mantém vivas tradições negras do Brasil em pleno coração da Região Metropolitana de Belo Horizonte. $\mathrm{O}$ grupo tem a origem ligada ao negro Camilo Silvério, então escravo que chegou a terras mineiras no final do século XIX. É a partir de seu filho, Artur Camilo Silvério que as informações sobre a formação da Comunidade ganham corpo. Sua personalidade forte, enriquecida pela intensidade da religiosidade aprendida com seus pais, funcionou como elemento aglutinador do grupo familiar. Artur Camilo Silvério é o fundador da Comunidade dos Arturos, já no nome podendo-se atestar a força da ancestralidade que é o "arcabouço mantenedor da vitalidade dos Arturos contemporâneos" (GOMES; PEREIRA, 2000, p. 163). Desde então, são mais de 120 anos de tradição. Atualmente os Arturos constituem uma comunidade com mais de 50 famílias, aproximadamente 400 descendentes, em sua maioria instalada em seis hectares de terra no local denominado Domingos Pereira, em Contagem.

O modo de ser Arturo se expressa fundamentalmente nas manifestações artísticoculturais e celebrações do Sagrado que a comunidade preserva e recria. A festa para os

1 Percepção formada a partir da experiência de cinco anos da pesquisadora como professora do ensino fundamental da Rede Municipal de Contagem/MG. 
Arturos é "fator de aliança e elemento agregador da comunidade" (GOMES; PEREIRA, 2000, p. 215), assim, a análise do calendário festivo dos Arturos nos possibilitou perceber a dimensão da importância destas festas para a comunidade, principalmente a do Reinado de Nossa Senhora do Rosário², na qual a religiosidade da comunidade transborda e seus integrantes se transmutam em "filhos do Rosário".

Pretendíamos, então, entender como se daria o acesso à Festa do Rosário pelos integrantes da comunidade. Buscamos dialogar com estudos sobre a Comunidade dos Arturos, e, a partir do que já tinha sido proposto, trazer à tona sob a lente do Lazer aquilo que emerge das relações dos Arturos com suas festas e com o mundo.

Trazendo para o centro da conversa a prática festiva seria possível compreender as festividades como reveladoras de identidades que se expressam no envolvimento, participação, aprendizagem e experiência cultural. Estudar o Lazer tornou-se, assim, fundamental, entendendo-o aqui como perspectiva de olhar que busca romper com dicotomias, que permite olhar para o cotidiano rompendo com os dualismos trabalho/tempo livre; trabalho/cultura.

Nossa pesquisa teve caráter qualitativo. $O$ estudo de caso numa perspectiva etnográfica mostrou-se a abordagem metodológica mais adequada, trazendo a possibilidade de retratar situações que emergiram das relações e na participação da comunidade nos festejos e os reflexos em sua cultura, percebendo esta cultura, como sugere Clifford (1998, p. 19), como uma construção multivocal, que percebe a diferença como um "efeito de um sincretismo inventivo". Seguindo a sugestão de Velho (2010), decidimos "correr o risco", colocando-nos como duplos aprendizes: dos nossos mestres acadêmicos e dos nossos mestres no campo, buscando construir não uma etnografia que representasse ou espelhasse os Arturos, mas que "atestasse" sua presença, que fosse, portanto, "participante da presença e que, por isso mesmo, não pretendesse se confundir com ela". Não foi o caso de tornar-nos Arturos, buscamos "não tanto o estudo de pessoas, e sim um modo de estudar com as pessoas"3.

A partir deste entendimento do fazer etnográfico buscamos, durante os três meses no contato direto e outros nove meses em visitas esporádicas na comunidade, entre 2011 e 2012, observar e participar do cotidiano de alguns Arturos: crianças, jovens e adultos, bem como da Festa do Reinado de Nossa Senhora do Rosário, desde sua preparação, organização e realização. Adotamos a observação participante como método de coleta de dados, utilizando o caderno de campo e entrevistas informais e semiestruturadas. Nosso projeto de pesquisa foi analisado pelo Conselho de Ética da UFMG e nossos Termos de Consentimento Livre e Esclarecido aprovados para utilização tanto com as crianças como com os adultos.

Para compreendermos melhor todo esse envolvimento dos Arturos com as festas, buscamos na Antropologia um aporte teórico relacional, focado na "pessoa inteira" - tão histórica quanto subjetiva -, no sentido proposto por Christina Toren (2001, 2010, 2012), entrelaçada em uma historicidade engajada, participativa, "(en)corporada". Para Toren, a forma como participamos da vida social é a própria chave de compreensão no mundo. Procuramos entender como na partilha das relações sociais constituimo-nos cada um e todos nós; provocados a tomar consciência de uma diversidade de histórias de relações que nos desafiam a compreender como nos tornamos o que somos (TOREN, 2001, p. 156).

2 Festa principal para a comunidade. Acontece anualmente em outubro.

3 VELHO, Otávio. Trabalhos de campo: antinomias e estradas de ferro. Aula inaugural no Instituto de Filosofia e Ciências Humanas da Universidade do Estado do Rio de Janeiro. Rio de Janeiro: UERJ, mar. 2006. 
Com esse sentido, em especial provocados pelos estudos de Jean Lave (1991; 1993; 1996; 2008), buscamos ampliar o foco de compreensão da escola, movendo-nos em direção a outros contextos de relações sociais.

A aproximação das pessoas, em seus contextos e de suas práticas, nos provocou um deslocamento de uma discussão centrada no ensinar, nas metodologias de ensino e na escolarização do conhecimento. Isto nos reforça um entendimento de que vivemos mergulhados em experiências culturais e implica-nos compreender que o acesso ao conhecimento é indissociável da possibilidade de sua realização; que o conhecimento é indissociável das formas de participação e de produção de uma vida coletiva.

No sentido proposto pelo antropólogo Tim Ingold (2010), aprendemos porque pousamos nos ombros de nossos antepassados; porque temos relações a copiar e práticas a repetir. Aprendemos porque ao repetir e copiar participamos de uma produção inventiva e criativa da vida. Aprendemos porque em nossos envolvimentos cotidianos emergem possibilidades de produção de si mesmo e da vida social.

Estes aportes teóricos nos levaram a um reencontro com o livro Casa de Escola, do antropólogo Carlos Rodrigues Brandão (1983), fazendo-nos perceber que o "começo de tudo é a relação", que a gente descobre o "conhecimento quando começa a exercê-lo".

O conhecimento, assim compreendido, não é o pressuposto da prática. Ao contrário, é a prática social que faz emergir o conhecimento, que se realiza coletivamente. Para Joana Overing (1999), o aprender está sempre ligado aos processos pelos quais os conhecimentos se realizam. Não está em uma única pessoa que o repassa para os demais. $\mathrm{O}$ conhecimento emerge dos processos de viver culturalmente, em que se revela como totalidade encarnada, e só pode ser compreendido em um fluxo de relações.

Com sentido semelhante, Antonella Tassinari ${ }^{4}$, ao problematizar a escola em contextos indígenas, assinala o cuidado para não se naturalizar a redução do convívio social das crianças aos processos de institucionalização dos "espaços infantis", sob o risco de também naturalizarmos mundos infantis separados e específicos. Provoca-nos pensar que isto, de forma paradoxal, pode privar as crianças do desenvolvimento de sua autonomia frente ao conhecimento, das próprias condições de aprendizagens, das habilidades e das inventividades necessárias à vida social, em suas diferentes formas de vivê-la.

Tais reflexões não se contrapõem à importância da escola e do direito à escolarização. Nossa intenção é propor um alargamento do entendimento de educação e das relações possíveis, também, no contexto escolar, provocando um estranhamento de uma ideia de escolarização:

[...] restrita ao submetimento de pessoas, conhecimentos, sensibilidades e valores aos imperativos escolares, onde os processos de ensinar e aprender se revelam com fim em si mesmo, e a Escola passa a ser vista como o locus por excelência, onde tudo, por transposição, pode ser ensinado e aprendido 5 .

Há situações de aprendizagem que emergem da participação e do envolvimento, numa relação tácita, na qual se aprende imitando, experimentando e improvisando respostas que exigem envolvimento e participação.

4 TASSINARI, Antonella. Múltiplas Infâncias: o que a criança indígena pode ensinar para quem já foi à escola ou A Sociedade contra a Escola. Trabalho apresentado no 33ํㅡㄹ Encontro Anual da Anpocs, 26-30 out. 2009. 
Propomos, com este artigo, descrever aspectos do cotidiano da Comunidade dos Arturos que se revelam em experiências culturais e que fazem emergir uma riqueza de relações, conhecimentos e desafios para uma vida em comum. As respostas encontradas ganharam centralidade e visibilidade não apenas em sujeitos tomados de forma isolada, nem em uma estrutura estática de signos determinantes da organização da vida social. Nosso foco analítico voltou-se para uma prática social, que também emerge da totalidade das experiências cotidianas: a Festa de Nossa Senhora do Rosário.

\section{FESTA E COTIDIANO: UM CANTAR E UM DANÇAR QUE CONVIDAM À REZA, À LUTA E À BRINCADEIRA}

Para conhecer os Arturos, buscamos enfocar aspectos marcantes no universo da Festa de Nossa Senhora do Rosário, discutindo como a participação neste contexto produz um processo identitário fundamental para reconhecer-se e tornar-se um Arturo. Cada gesto, cada detalhe, a batida das caixas, o ritmo da dança, requer atenção e aprendizado.

Aprendem, pouco a pouco, a posicionar-se no mundo, envolvendo-se no contexto da Festa e seus artefatos culturais. Cada fazer adquire significado e importância, reproduzindo-se de forma criativa e inventiva, cotidianamente.

Os Arturos têm uma ancestralidade forte, de antepassados que vieram para o Brasil, cujas lembranças trazem à presença uma história de luta e resistência, que revivem e narram em seu cotidiano. A vivência do Congado ${ }^{6}$ contribui para os Arturos formarem um quadro amplo de preservação e reelaboração das heranças dos antepassados. Em seus cantos e orações, resgatam a linguagem dos antepassados entrelaçada com a linguagem aprendida na vida cotidiana, tendo como elo a experiência comunitária, gerando identidade para cada um de seus integrantes.

Como eles próprios dizem, o respeito pelo "que nossos pais fizeram" orienta a vida da comunidade, sem coibir a expressão de novas relações com o mundo. Serve como um porto seguro, um momento sagrado. Promover festas significa para os Arturos não apenas relembrar o passado, mas a criação e a recriação de uma história sagrada de sua família, e de seus mitos de origem. Festejar é o próprio sentido da vida. Assim, o Congado é uma festa, mas também um desafio: chama para reza e para luta. $O$ Ser dançante do Congado disponibiliza seu corpo para que nele ocorram as forças da ancestralidade. Ao mesmo tempo em que trabalham e enfrentam as dificuldades cotidianas, os "filhos do Rosário" festejam, fazendo transbordar uma consciência coletiva, que os faz Arturos, filhos de África.

A Festa do Rosário se abre como uma fresta no tempo e instaura um espaço-tempo mítico e narrativo. Neste contexto, a educação das crianças apresenta-se como um dos pontos mais profícuos para o entendimento da estrutura social dos Arturos, pois em casa elas aprendem desde pequeninas a linguagem através das danças do Congado, compartilhada com seus antepassados.

\footnotetext{
6 Festejo popular afro-brasileiro.

7 Fala do Sr. João Batista, neto de Artur Camilo. No texto, as falas de nossos "anfitriões" Arturos serão destacadas em itálico e entre aspas. Obtivemos autorização da Comunidade para reproduzir as falas e nomes reais dos adultos. Alguns deles, pessoas públicas e notórias do Congado Mineiro, não objetaram em ter suas falas reproduzidas. Por um cuidado ético, utilizamos nomes fictícios para as crianças.
} 
A convivência se apresenta como um jogo que depende do outro para que aconteça. Festejar para as crianças Arturos emerge como brincadeira de preparar as bandeirinhas que enfeitarão o terreiro e a capelinha e ao dançar, cantar, bater caixa, experimentando movimentos, o corpo, a música, a dança, a festa.

\section{NAS FRESTAS DO TEMPO, UM CALENDÁRIO FESTIVO: SENDO CRIANÇAS NA RELAÇÃO COM OS ADULTOS - APRENDENDO A SER UM ARTURO}

Naquela noite a comunidade se encontrou na porta da Capela. 0 som dos tambores foi chamando a todos. Devagarzinho, um a um, famílias, casais, jovens iam chegando. Os mais velhos chegavam primeiro, seguidos por alguns pequeninos que graciosamente os acompanhavam imitando jeitos de andar, de cumprimentar, de usar o terço, de carregar o tambor.

As crianças, ao mesmo tempo em que carregam os instrumentos com a mesma seriedade dos avós, também os transformam em "espadas". Nesse jogo entre o real e 0 imaginário, como observa Levindo Carvalho (2007), ensaiam-se papéis, experimenta-se uma socialidade local, adquirem-se habilidades necessárias à convivência social, incorporando hábitos, sentidos e conhecimentos de seu grupo social. Durante toda a preparação, e mesmo durante os três dias da Festa de Nossa Senhora do Rosário, evidencia-se que ali as crianças não estão destinadas a ocupar um lugar apenas de espectadores. Tanto absorvem como são absorvidas pela vivência daquela prática festiva, possibilitando a participação e a percepção da Festa como experiência cultural.

Ocupando lugares simbólicos importantes na Festa e em sua organização, as crianças paulatinamente apreendem o que constitui os saberes e fazeres do Congado. A presença constante nas festas e rituais e o envolvimento com as práticas conferem aos pequenos Arturos, no sentido de Lave (1991), um acesso pleno e legítimo. Já nos primeiros contatos com a comunidade percebemos isso. Os primeiros a nos chamarem ao convívio foram Anita, Fábio e Gleice ${ }^{8}$. Nesta relação entre real e imaginário, de pronto se transformaram em nossos "pesquisadores mirins". Foi interessante que não foi nossa a escolha. Naturalmente eles se elegeram os "pesquisadores dos Arturos" e achamos interessante não romper com esta lógica, deixando que ela nos conduzisse. Ficamos intrigados em descobrir aonde chegaríamos.

Nossas outras duas anfitriãs ${ }^{9}$, participantes ativas da pesquisa, também se elegeram. A acolhida e disponibilidade das duas cativaram nossa atenção e deixamos que elas nos conduzissem no percurso da pesquisa.

\subsection{Preparar a festa: compartilhando histórias e segredos}

É impensável imaginar a Festa sem bandeirinhas. A igrejinha precisa estar enfeitada e bonita. É instituído entre os Arturos que a tarefa de pregar as bandeirinhas é função das crianças, e elas, assim, sentem-se responsáveis pela Festa. Uma mistura de prazer com obrigação.

8 Bisnetos e trineta do patriarca Artur Camilo (nomes fictícios). 
Para fazer parte da prática festiva, quanto mais participativo, mais preparado, numa retroalimentação entre o que está posto e a aprendizagem. Não é possível saber com precisão onde começa um e termina o outro. Aprende-se fazendo, torna-se um Arturo sem ter sido ensinado como sê-lo: "Ser Arturo é um jeito de ser que a gente descobre e aprende aqui, pregando bandeirinha, ouvindo as histórias, cantando e rezando. Foi assim que eu aprendi. Não sei como explicar. Sei que é assim" (D. Tetane, filha de Artur Camilo, out/2012).

Outra prática fundamental entre as crianças Arturos é a batida das caixas. No dia da Festa, durante o almoço, uma criança parou na frente do Capitão da guarda do Congo e observou atentamente sua batida na caixa. Com sua caixinha pendurada sobre o ombro tentou imitar os movimentos com suas baquetas e reproduzir o som que ouviu. E é assim também em casa, como contou sua tia: "Pega o cabo de vassoura, transforma sua vó em Rainha, pega a tampa da panela e a colher e se transforma em caixeiro. Ele sabe todas as músicas e quer que todos da família cantem enquanto ele dita o ritmo com a caixa" (Juliana Luz, bisneta do patriarca Artur Camilo, out. 2012).

Participando da Festa, levando e trazendo essas experiências para seu cotidiano, os Arturos vão produzindo processos de atuar de forma efetiva e qualificada na comunidade.

Essa construção identitária é de suma importância para o sujeito, visto que será a partir dela que ele se sentirá autor de sua história. Zerbo (1982) afirma que não se pode amar aquilo que não se conhece. Para Munanga (2002), a identidade cultural se constrói com base na tomada de consciência das diferenças provinda das particularidades históricas, culturais, religiosas, sociais, regionais etc. A identidade não é assim, fechada, imune ao contato, alheia aos movimentos das relações cotidianas. Ela é plural, afetada por relações. Constituí-la pressupõe um reconhecer-se, a partir de seus pares, a partir do outro e a partir do que emerge destas relações.

\subsection{Ser-dançante do Congado: a materialidade e a força dos rituais}

A Festa tem seus rituais que marcam o estar na Festa, o ser a Festa. O levantamento dos Mastros, o Candombe, a Matina, o Cortejo, a Missa Conga, o Almoço, o pagamento de Promessas, o Congo Mirim e o encerramento são descritos por nossos anfitriões com uma riqueza de detalhes que transborda toda a importância e força deles para cada um e para a comunidade.

Quinze dias antes do dia do início da festa acontece o levantamento dos Mastros ${ }^{10}$, como forma de anunciar para a cidade que a Festa está chegando. Símbolo de respeito e admiração pelos Arturos, os Mastros são enfeitados com fitas coloridas que identificam os Santos homenageados. Esta conexão entre o divino e o terreno envolve todo um ritual de Fé: "O mastro é nossa proteção. É a proteção para a nossa Festa. Representa a relação entre o céu e a terra. Hasteá-lo significa pedir permissão ao Alto para realizarmos nossa Festa" (Ana Paula Francisca da Silva, bisneta do patriarca Artur Camilo, out. 2012).

$\mathrm{Na}$ noite do primeiro dia da Festa aconteceu o Candombe ${ }^{11}$. Na capelinha, primeiro entrou o Sr. Mario, seguido por João Batista e Bengala ${ }^{12}$ para esquentarem os couros dos tambores. É como se estivessem pedindo permissão aos antepassados para tocarem os três

10 No texto, os rituais e objetos da Festa serão destacados por negrito. 
Tambores Sagrados. Pediu-se bênção para as crianças e para os mais velhos. Depois adultos se enfrentaram nas cantigas, observados com entusiasmo e alegria pelas crianças.

No segundo dia da Festa, aconteceu a Matina. Antes de o sol nascer os Arturos se encontraram na porta da capelinha para abrir os caminhos para a Grande Festa.

Depois da Matina e o retorno para casa, às nove horas, os foguetes chamaram. Era hora do cortejo até a igreja para a Missa Conga. A comunidade, já colorida de branco, rosa e azul, ficou ainda mais reluzente, com todos uniformizados. Foi um vaivém que transbordava alegria, sonoridade e fé.

Durante o trajeto algumas guardas convidadas foram se juntando ao Cortejo numa mistura de som e cores extraordinária. A entrada das guardas foi marcada por um romper do silêncio com a batida das caixas que, em um primeiro momento, amedrontou e depois se transformou em um eco de Fé e energia. 0 cheiro do incenso; o som das caixas; a batida das gungas; os hinos... Tudo criou uma atmosfera indescritivel.

Para a despedida, a igreja ecoou o canto das flores de Nossa Senhora do Rosário, em uma mistura de real e imaginário, como se pétalas efetivamente caíssem do céu.

Enquanto acontecia o retorno do cortejo, as cozinhas da comunidade estavam em polvorosa. $\mathrm{O}$ almoço é um momento muito importante da Festa. Servir bem e com fartura é uma preocupação de todos os Arturos e uma característica marcante das festas na comunidade, cultuada e vivida em plena confraternização entre o sagrado, 0 alimento e os sujeitos.

Almoço servido era hora de reunir o Congo Mirim ${ }^{13}$. Ao chamado do capitão, mais de vinte crianças e adolescentes se reuniram na porta da capelinha. De todos os cantos apareciam crianças devidamente uniformizadas, carregando suas caixas, suas gungas, além dos bicos e chupetas. Seus olhos se fixavam nos movimentos dos adolescentes e jovens. Era uma mistura de admiração e atenção. Os detalhes na tentativa de imitar cada gesto eram impressionantes. O mundo externo pouco importava: flashes, aplausos... nada tirava a atenção dos pequeninos dos movimentos de seus mestres.

Os jovens caixeiros observados pelas crianças, através de sua batida nas caixas davam suporte ao processo de aprendizagem das crianças, orientando seus gestos, e consequentemente fazendo-os aprender. Os adolescentes guiavam os passos dos futuros caixeiros Arturos. E foi exatamente o engajamento atento e situado na prática que permitiu aos pequenos constituírem suas habilidades (INGOLD, 2001), como parte do processo de constituir-se um Arturo.

No fim da tarde, começou a preparação para a Procissão em homenagem a Nossa Senhora do Rosário. Os andores dos santos ${ }^{14}$ foram carregados pelos pagadores de promessa, que descalços, em prece, agradeciam as graças recebidas.

A Festa de Nossa Senhora do Rosário teve, em seu último dia, a missa na Capelinha e o cortejo para a descida dos mastros. No final da noite, uma sensação de dever cumprido e saudade tomou conta de todos. 
A organização cotidiana da comunidade faz com que todos seus integrantes tenham permanentemente sob os olhos um repertório completo de exemplos em que se inspirar, modelos para imitar. Em cada momento da Festa, as crianças, e não somente elas, observam e põem em ação os gestos, os cantos, as rezas, as danças. Nas festas e rituais, acontecem incentivos e correções mútuas dentro da comunidade. A observação atenta e silenciosa, 0 imitar inicialmente desastrado e sem jeito se tornam, no contexto da aprendizagem, elementos essenciais das relações na Festa, pois comunicam o saber Arturo.

\subsection{A relação com os Objetos, com as Pessoas, com os Santos}

A todo momento, a relação dos Arturos com os objetos se tornou bastante explícita. A convivência cotidiana dos Arturos com todos os elementos que envolvem a Festa foi especialmente significativa porque tornou visível uma substancial parte do patrimônio cultural da sua prática festiva.

O batido da Caixa chamou pra dança: "Ver estas caixas no chão ou penduradas no ombro dos caixeiros é saber que ali tem um Arturo" (Anita, bisneta do patriarca Artur Camilo, out. 2012, nome fictício). O Patangome ou chique chique trouxe lembranças do Tio Titoco ${ }^{15}$, 0 rei do patangome da comunidade. As crianças contam que sabem tocá-lo devido "a ficar bem pertinho do Titoco vendo-o tocar". Outros se referiram ao som da Gunga: "Parecem sininhos tocando" (Anita, bisneta, do patriarca Artur Camilo, out. 2012, nome fictício). Segurar um Bastão era sinônimo de poder. Somente com o bastão nas mãos um Capitão pode puxar as músicas. As crianças disseram que o bastão é igual o Rosário: "Se não tiver com o bastão na mão não é capitão, se não tiver um Rosário não é um Arturo" (Fábio, bisneto do patriarca Artur Camilo, out. 2012). O Rosário é sinônimo de proteção para os Arturos. Estar com o Rosário representa estar protegido do mundo.

Os Reis e Rainhas foram reverenciados. São personagens principais da Festa. 0 respeito pelos reis e rainhas durante a Festa se estende ao cotidiano da comunidade. São conselheiros, ombro amigo, pais e mães de todos os Arturos.

\section{PARA CONTINUAR O DIÁLOGO: A OBSERVAÇÃO COMO PRÁTICA DE APRENDIZAGEM}

A riqueza dos dados elaborados no campo de pesquisa em diálogo com as pessoas mostrou que, tanto em suas narrativas como em sua participação na prática festiva, nossos anfitriões utilizam a observação como ação fundamental para suas aprendizagens. Como também observou Bergo (2011, p. 230), "em nossa tradição de pensamento 0 ato de observar é desvalorizado em detrimento da ação e da atividade, especialmente em se tratando da aprendizagem de algo que exige habilidades motoras, como é o caso de aprender a tocar instrumentos musicais".

Destacamos, nesse sentido, como a observação é levada a efeito pelas crianças Arturos. Implica uma diversidade de ações: ver, ouvir, envolver-se, imitar, realizar. Na observação aprendem a bater a caixa, a balançar o patangome, a dançar com a gunga nos pés. E este aprendizado é algo bastante concreto. Longe de ser uma atividade passiva, envolve atenção, presença e relação. 
Mas a observação também é uma construção relacional, que requer aprendizado e constituição de um olhar e de uma presença sensível, cuidadosa, atenta e, por isto, reflexiva. Participar da Festa, saber tocar os instrumentos, proteger-se com o Rosário, rezar junto ao Altar pedindo proteção aos Santos é mais que uma estratégia para aprender a ser a Festa. É uma forma de se conectar aos fundamentos e rituais do Congado, participando diretamente em sua prática.

As ações produzidas pelos pequenos Arturos durante a Festa e no cotidiano da comunidade podem parecer aos olhos dos visitantes e estranhos àquela prática um processo meramente repetitivo, num sentido bastante limitado do termo. Mas não é isso que acontece. Esta repetição é um procedimento recursivo, no qual cada gesto produzido faz referência à outra ação.

Essas ideias remetem ao conceito de "ensaio" proposto por Tim Ingold (2000, p. 418). Para o autor, ensaio é o processo de "repetir o mesmo movimento como uma preparação ou condução para o seu desempenho prático". O ensaio é, então, uma maneira de entender a prática, um processo de aprender a partir da imersão no que se está praticando ou, como ele mesmo diz (INGOLD, 2000, p. 416), é "[...] um processo de habilitação, no qual a aprendizagem é inseparável do fazer".

Os mais velhos operam, empiricamente, seus saberes e habilidades a partir das experiências acumuladas em anos de prática. Eles se comportam de modo muito semelhante ao modo como viram seus pais e avós agirem. Acabam por reproduzir o modelo em que eles mesmos aprenderam.

De modo geral, é por meio de observações, críticas, encorajamentos ou apenas pela presença que os mais experientes se relacionam com aqueles que começam a trilhar seus caminhos no Congado. A partir da reflexão sobre esses aspectos da prática festiva na comunidade, percebemos que os modos de aprendizagem que fazem parte do repertório partilhado entre os Arturos não acontecem a partir do seu ensino explícito, mas da visibilidade que tais ações vão assumindo no dia a dia da comunidade. Cada vez que tocam, cantam, dançam, batem caixa, os Arturos não estão fazendo sempre a mesma coisa. Nos momentos que estão conversando, ouvindo histórias, trocando informações, batendo caixas, tocando o patangome, eles estão se habilitando, se apropriando do modo de ser Arturo. Assim, mais que repetir ou reproduzir, os Arturos exercitam e experimentam a Festa e, desse modo, podem aprendê-la. E, a partir desta aprendizagem se constituem Arturos. Um fazer/aprender que envolve relações de poder, acordos, negociações e conflitos inerentes à vida social. É a partir desse envolvimento que o Arturo aprende os gestos, os significados, as emoções, as disposições corporais e identidades que o produzem Arturo.

A Festa do Rosário permanece até hoje porque é compromisso de amor, uma função sagrada recebida pelos ancestrais, porque é nela e partir dela que emerge o ser Arturo que brilha dos olhos de cada integrante da comunidade.

E este "brilho nos olhos" possibilita, como sugere Nilma Lino Gomes (2003, p. 80),

[...] a construção de um "nós", de uma história e de uma identidade. Diz respeito à consciência cultural, à estética, à corporeidade, à musicalidade, à religiosidade, à vivência da negritude, marcadas por um processo de africanidade e recriação cultural. Esse "nós" possibilita o posicionamento de negro diante do outro e destaca aspectos relevantes da sua história e de sua ancestralidade. 
A preparação e a organização da Festa de Nossa Senhora do Rosário na comunidade revelaram mais sobre a complexidade da prática festiva do que o próprio evento em si. No cotidiano de meus anfitriões, a fé que transborda durante os festejos se concretiza, os laços afetivos evidenciados nos festejos se fortalecem, as relações de respeito, de afeto e também de poder aparecem com maior clareza.

Por fim, é necessário destacar que nosso estudo não pretendeu apresentar o passo a passo para a construção de uma identidade negra positiva, ou como tornar-se um Arturo, mas permitir novos olhares para a prática do Congado, para os sujeitos da pesquisa e para nós mesmos, nas nossas relações cotidianas de aprendizagem.

A experiência na Comunidade dos Arturos nos fez refletir que efetivamente urge um deslocamento da discussão centrada no ensinar, nas metodologias de ensino e na escolarização do conhecimento. É importante que pensemos que o acesso ao conhecimento é indissociável da possibilidade de sua realização; que o conhecimento é indissociável das formas de participação e de produção de uma vida coletiva.

O dia a dia com os Arturos reafirmou nossa ideia de que o conhecimento não é o pressuposto da prática. Ao contrário, é a prática social que faz emergir o conhecimento, que se realiza coletivamente. Ele não está em uma única pessoa que o repassa para os demais. 0 conhecimento emerge dos processos de viver culturalmente e só pode ser compreendido em um fluxo de relações.

Reafirmamos que nossa proposta reflexiva não se contrapõe à importância da escola e ao direito à escolarização. Nossa intenção foi propor um alargamento do entendimento de educação e das relações possíveis, também, no contexto escolar. Acreditamos que esse olhar mais alargado possa contribuir muito na construção de uma escola mais humana, sensível e democrática.

\section{REFERÊNCIAS}

BERGO, Renata Silva. Quando o santo chama: o terreiro de umbanda como contexto de aprendizagem na prática. 2011. 249f. Tese (Doutorado). - Faculdade de Educação, Universidade Federal de Minas Gerais, Belo Horizonte, 2011.

BRANDÃO, Carlos Rodrigues. Casa de escola. Campinas: Papirus, 1983.

BRASIL. Lei Federal n. 10.639 de 9 de janeiro de 2003. Disponível em: <http://www.planalto.gov. br/ccivil 03/Leis/2003/L10.639.htm >. Acesso em: 13 set. 2015.

CARVALHO, Levindo Diniz. Imagens da infância: brincadeiras, brinquedo e cultura. Dissertação (Mestrado em Educação) - Faculdade de Educação, Universidade Federal de Minas Gerais, Belo Horizonte, 2007.

CLIFFORD, James. A experiência etnográfica: antropologia e literatura no século XX. Rio de Janeiro: Editora UFRJ, 1998.

GOMES, Nilma Lino. Cultura negra e educação. Revista Brasileira de Educação, n.23, p.7585, ago 2003. Disponível em: <http://www.scielo.br/pdf/rbedu/n23/n23a05.pdf >. Acesso em: 19 set.2010.

GOMES, Núbia Pereira de Magalhães; PEREIRA, Edmilson de Almeida. Negras raízes mineiras: os Arturos. 2. ed. Juiz de Fora: Universidade Federal de Juiz de Fora, 2000. 
INGOLD, Tim. Culture, perception and cognition. In: INGOLD, Tim. The perception of the environment: essays on livelihood, dwelling and skill. New York: Routledge, 2000. Chap. 9, p. 157-171.

INGOLD, Tim. From the transmission of representations to the education of attention.

In: INGOLD, Tim. The debated mind: evolutionary psychology versus ethnography. Oxford: Harvey Whitehouse, 2001.

INGOLD, Tim. Da transmissão de representações à educação da atenção. Educação, v. 33, n. 1, p. 6-25, jan./abr. 2010.

LAVE, Jean; WENGER, Etienne. Situated learning: legitimate peripheral participation. Cambridge: Cambridge University, 1991.

LAVE, Jean. The practice of learning. In: CHAIKLIN, S.; LAVE, J. (Eds.). Understanding Practice: perspective on activity and context. Cambridge: Cambridge University Press, 1993. p.3-32.

LAVE, Jean. Teaching, as learning, in practice. Mind, Culture and Activity, v. 3, n. 3, p. 149164, 1996.

LAVE, Jean. Epilogue: situated learning and changing practice. In: AMIN, Ash; ROBERTS, Joanne. (Eds.). Community, economic, creativity and organization. Oxford: Oxford University, 2008. p. 283-296.

MUNANGA, Kabengele. A identidade negra no contexto da globalização. Revista Ethnos Brasil, v. 1, n. 1, p.11-20, mar. 2002.

OVERING, Joanna. Elogio do cotidiano: a confiança e a arte da vida social em uma comunidade amazônica. Mana, v. 5, n. 1, p. 81-107, 1999.

TOREN, Christina. The Child in Mind. In: WHITEHOUSE, Harvey. The debated mind: evolutionary psychology versus ethnography. Oxford: Berg, 2001.p.155-179.

TOREN, Christina. A matéria da imaginação: o que podemos aprender com as crianças fijianas sobre suas vidas com os adultos. Horizontes Antropológicos, v. 16, n. 34, p. 19-48, jul./dez. 2010.

TOREN, Christina. Antropologia e Psicologia. Revista Brasileira de Ciências Sociais, v. 27, n. 80, p. 21-36, out. 2012.

VELHO, Otávio. "Coram Riscos!": depoimento. Revista Anthropológicas, v. 14, n.21, p. 329-341, 2010. Entrevista concedida a Flávia F. Pires e Silvia G. Nogueira. Disponível em: <www.ufpe.br/ revistaanthropológicas/index.php/revista/article/.../150>. Acesso em: 8 jan. 2013.

ZERBO, Joseph K. (Org.). História geral da África. São Paulo: Ática, 1982. 